\title{
The 2020 Arctic ozone depletion and signs of its effect on the ozone column at lower latitudes
}

\author{
Boyan Petkov ${ }^{1,2} \cdot$ Vito Vitale $^{2} \cdot$ Piero Di Carlo $^{1,3} \cdot$ Mauro Mazzola $^{2} \cdot$ Angelo Lupi $^{2}$. \\ Henri Diémoz ${ }^{4}$ - Ilias Fountoulakis ${ }^{4} \cdot$ Oxana Drofa $^{5}$. Daniele Mastrangelo ${ }^{5}$. \\ Giuseppe Rocco Casale ${ }^{6}$. Anna Maria Siani ${ }^{6}$
}

Received: 3 May 2021 / Accepted: 28 July 2021 / Published online: 31 August 2021

(c) The Author(s), under exclusive licence to Springer Nature Switzerland AG 2021

\begin{abstract}
The present study discusses the effect of the ozone depletion that occurred over the Arctic in 2020 on the ozone column in central and southern Europe by analysing a data set obtained from ground-based measurements at six stations placed from 79 to $42^{\circ} \mathrm{N}$. Over the northernmost site (Ny-Ålesund), the ozone column decreased by about $45 \%$ compared to the climatological average at the beginning of April, and its values returned to the normal levels at the end of the month. Southwards, the anomaly gradually reduced to nearly $15 \%$ at $42^{\circ} \mathrm{N}$ (Rome) and the ozone minimum was detected with a delay from about 6 days at $65^{\circ} \mathrm{N}$ to 20 days at $42^{\circ} \mathrm{N}$. At the same time, the evolution of the ozone column at the considered stations placed below the polar circle corresponded to that observed at $\mathrm{Ny}$ Alesund, but at $42^{\circ}-46^{\circ} \mathrm{N}$, the ozone column turned back to the typical values at the end of May. This similarity in the ozone evolutional patterns at different latitudes and the gradually increasing delay of the minimum occurrences towards the south allows the assumption that the ozone columns at lower latitudes were affected by the phenomenon in the Arctic. The ozone decrease observed at Aosta $\left(46^{\circ} \mathrm{N}\right)$ combined with predominantly cloud-free conditions resulted in about an $18 \%$ increase in the erythemally weighted solar ultraviolet irradiance reaching the Earth's surface in May.
\end{abstract}

Keywords Polar vortex - Arctic ozone - Relationships between polar and mid-latitudes · Solar ultraviolet irradiance

\section{Introduction}

Ozone is an important atmospheric component that plays a significant role in the thermal structure of the stratosphere and, hence, affects the dynamical processes in the middle atmosphere. On the other hand, absorption of solar ultraviolet (UV) radiation, especially in

Giuseppe Rocco Casale is now independent scientist

Boyan Petkov

b.petkov@isac.cnr.it

Extended author information available on the last page of the article 
UV-C (100-280 nm) and in the 280-300 $\mathrm{nm}$ of the UV-B range $(280-315 \mathrm{~nm})$ by ozone protects life on the Earth from this harmful agent. For that reason, ozone has been a subject of intensive studies since the beginning of the last century. In the middle of the 1980s, appreciable ozone depletion phenomena were observed over Antarctica during the austral springs (Farman et al. 1985; Solomon et al. 1986; WMO 2018). These events were considered as being a result of the emission of ozone-depleting substances into the atmosphere and the polar vortex, which usually appears in winter and breaks up in late spring. The polar vortex turns out to be a strong barrier for the air mass exchange between polar and mid-latitude areas. In the absence of the solar light, the reduction of meridional exchange leads to the cooling of the polar stratosphere enveloped by the vortex. A decrease of the temperature below about $196 \mathrm{~K}$ is the main factor for the formation of polar stratospheric clouds that, in turn, contribute to the intensification of the processes responsible for the chemical ozone destruction (Molina and Rowland 1974). As a result, the ozone content in a large stratosphere zone surrounded by the vortex appreciably diminished.

Monitoring of the Antarctic atmosphere showed that the polar vortex is quite stable, slightly varying from year to year, and usually covers the entire Antarctic region. In contrast, the Arctic vortex turns out to be frequently perturbed by dynamical processes, like Rossby waves (Hauchecorne et al. 2002) that impede the formation of a stable area with low ozone column content. However, in the past three decades, some strong ozone decreases have also occurred in the Arctic. The most pronounced events were observed in 1997, 2011, and 2020, with the last event being the strongest among them (Manney et al. 2011; Manney et al. 2020; Varotsos et al. 2012; Wohltmann et al. 2020; Dameris et al. 2021). Varotsos et al. (2020) concluded that such occurrences in the Arctic appear to be a complex phenomenon depending on the duration of the polar vortex, the extent of polar stratospheric clouds, and stratosphere temperature.

The decrease in the ozone column causes an increase in UV-B solar radiation reaching the ground, and such an increase was found to be about $14 \%$ in case of nearly $5 \%$ reduction of the ozone column at European mid-latitude areas in summer (Varotsos 1994). According to Bernhard et al. (2020), the decrease in the 2020 ozone column in the Arctic led to a corresponding increase in the surface solar UV irradiance by about 75\% in March and 25\% in April.

Various studies showed that the Arctic ozone depletions would be able to impact the ozone column at lower latitudes, as well (Knudsen and Grooß 2000; Hauchecorne et al. 2002; Koch et al. 2004; Petkov et al. 2016). Petkov et al. (2014) examined the effect of the 2011 Arctic ozone reduction on the ozone over central and southern Europe by analysing a large set of ground-based measurements. While the decrease in the ozone column at the northernmost site, Ny-Ålesund, placed at $79^{\circ} \mathrm{N}$ was about $40 \%$ regarding the climatological average, the corresponding decrease between $40^{\circ} \mathrm{N}$ and $50^{\circ} \mathrm{N}$ was $15-18 \%$. The latter reduction took place with a delay of almost 2 weeks relative to the ozone depletion in the Arctic, and the ozone evolution was similar to that observed in the Arctic, which occurrences led to the assumption about a cause-effect relationship between the Arctic and midlatitude phenomena. In this concern, the present study aims to examine the effect of the 2020 Arctic episode on ozone at lower latitudes, by applying a method similar to that for the 2011 phenomenon. 


\section{Data set, instrumentation, and methodological approaches}

The data of 6 ground-based stations provided by the World Ozone and UV Radiation Data Centre (WOUDC 2020) were considered to examine the behaviour of the ozone column over Europe after the deep Arctic ozone depletion in 2020. The stations are chosen to be distributed from the northernmost point available to a site at mid-latitude, and their coordinates are given in Table 1, while the corresponding geographical positions are exhibited in Fig. 5b. Total ozone measurements at the selected stations were performed mainly by Brewer or/and Dobson spectrophotometers (see Table 1). Besides, the UV-RAD radiometer has also been operating at Ny-Ålesund, and the Bentham spectroradiometer provides the spectral UV irradiance at Aosta.

The Dobson spectrophotometer (hereinafter referred to as Dobson) was the first instrument designed and used to determine the total ozone column in the atmosphere from the measurements of solar irradiance. Continuous observations by Dobson have been performed in Oxford, the UK since 1926 (Dobson 1968), while a global network of Dobsons has operated since 1957. Retrieval of total ozone by Dobsons is based on ratios among the irradiances at different wavelengths in the range $305-340 \mathrm{~nm}$.

The main disadvantages of Dobsons are their bulk and weight, and in most cases, they are manually operated. The Brewer spectrophotometer (hereinafter referred to as Brewer) was designed to retrieve the ozone column from both the direct sun (DS) and zenith sky (ZS) observation geometries in the UV-B band reaching the Earth's surface (Kerr et al. 1981; Brewer and Kerr 1973). Brewers are fully automated and have been routinely used since the 1980s for measurements of the total ozone column as a replacement of Dobsons. They perform nearly simultaneous DS measurements at five wavelengths $(306.3,310.1,313.5,316.8$, and $320.1 \mathrm{~nm})$, and then, ozone is retrieved from ratios among the irradiances at the four longest wavelengths (Siani et al. 2018). The accuracy in the measurements of Brewer and Dobson under cloudless skies was found to be about 1\% (Kerr et al. 1981; Van Roozendael et al. 1998), while the error in ZS measurement mode was 3-4\% (Vanicek 2006). The agreement between the ozone columns measured by collocated Brewer and Dobson is generally better than $1 \%$ (Garane et al. 2018).

The Bentham spectroradiometer was constructed to perform measurements of the spectral solar irradiance in the UV and visible regions. The sampling time, the

Table 1 Ground-based stations considered in the present study, their equipment and measurement period

\begin{tabular}{|c|c|c|}
\hline Station, country & Instrument & Period of observations \\
\hline \multirow[t]{2}{*}{ Ny-Ålesund $\left(78^{\circ} 56^{\prime} \mathrm{N}, 11^{\circ} 56^{\prime} \mathrm{E}\right)$, Norway } & Brewer MKIV 050 & $2017-2020$ \\
\hline & UV-RAD & $2008-2020$ \\
\hline \multirow[t]{2}{*}{ Vindeln $\left(64^{\circ} 14^{\prime} \mathrm{N}, 19^{\circ} 46^{\prime} \mathrm{E}\right)$, Sweden } & Brewer MKII 006 & $1996-2020$ \\
\hline & Dobson 030 & $1991-2020$ \\
\hline Norrköping $\left(58^{\circ} 35^{\prime} \mathrm{N}, 16^{\circ} 09^{\prime} \mathrm{E}\right)$, Sweden & Brewer MKIII 128 & $1988-2020$ \\
\hline \multirow[t]{2}{*}{ Hohenpeißenberg $\left(47^{\circ} 48^{\prime} \mathrm{N}, 11^{\circ} 01^{\prime} \mathrm{E}\right)$, Germany } & Brewer MK II 010 & 1984-2020 \\
\hline & Dobson 104 & $1967-2020$ \\
\hline \multirow[t]{2}{*}{ Aosta $\left(45^{\circ} 42^{\prime} \mathrm{N}, 07^{\circ} 22^{\prime} \mathrm{E}\right)$, Italy } & Brewer MKIV 066 & $2007-2020$ \\
\hline & Bentham 5541 & 2006-2020 \\
\hline Rome $\left(41^{\circ} 54^{\prime} \mathrm{N}, 12^{\circ} 31^{\prime} \mathrm{E}\right)$, Italy & Brewer MKIV 067 & $1992-2020$ \\
\hline
\end{tabular}


wavelength step, and the resolution of the obtained spectra are adjustable to the needs of the observations. The measurements made by the double monochromator Bentham DTMc300 with serial number 5541 (hereinafter referred to as Bentham 5541) have been used in the present study. Under usual operational conditions, the instrument performs measurements in the $290-500 \mathrm{~nm}$ wavelength range with a step of $0.25 \mathrm{~nm}$ and a full width at half maximum (FWHM) of the transmission function approximately $0.54 \mathrm{~nm}$. For wavelengths above $310 \mathrm{~nm}$ and solar zenith angles lower than $75^{\circ}$, the two-fold uncertainty in the measurements of Bentham 5541 is less than $4 \%$ (Fountoulakis et al. 2020a, b).

The narrow band filter radiometer UV-RAD was created to observe the UV irradiance and ozone column in polar regions (Petkov et al. 2006). The instrument measures the UV fluxes at 7 channels, each of them with an FWHM of about $1 \mathrm{~nm}$, and a procedure based on the Stamnes approach (Stamnes et al. 1991) was developed to extract the ozone column from the measurements.

In addition, data taken from the European Centre for Medium-Range Weather Forecasts (ECMWF 2021) were used to extract the potential vorticity (PV) that helped in illustrating the polar vortices. The corresponding distributions of the ozone column in the polar areas were presented through maps provided by the US National Aeronautics and Space Administration (NASA 2021).

Some parameters characterising the solar UV irradiance at the Earth's surface that are used for the discussion in Sect. 3.3 are introduced below. Erythemally weighted $\mathrm{UV}$ radiation is a common measure for the assessment of biological effects on humans. If $I(\lambda, t)$ is the solar UV irradiance at wavelength $\lambda$ reaching the Earth's surface at time $t$, the erythemal irradiance $I_{E}(t)$ is determined as:

$$
I_{E}(t)=\int_{280 n m}^{400 n m} I(\lambda, t) A(\lambda) d \lambda,
$$

where $A(\lambda)$ is the so-called erythemal action spectrum that represents the relative ability of radiation at wavelength $\lambda$ to cause an erythemal response in the human skin (CIE 1998). The maximum value of $A(\lambda)$ equal to 1 was defined for the wavelengths no longer than $300 \mathrm{~nm}$, and after them, $A(\lambda)$ rapidly decreases to about $10^{-4}$ at $400 \mathrm{~nm}$. The sensitivity of $I(\lambda, t)$ to the variations in the ozone column was quantified by Madronich (1993) through the radiation amplification factor (RAF) as:

$$
\frac{I(\lambda, t)}{I_{o}(\lambda, t)}=\left[\frac{Q(t)}{Q_{o}(t)}\right]^{-\mathrm{RAF}},
$$

where the solar irradiance $I(\lambda, t)$ corresponds to ozone column $Q(t)$, while $I_{o}(\lambda, t)$ to $Q_{o}(t)$. The RAF is usually determined from the observations and for $I_{E}(t)$ it was evaluated to be about 1.2 (Blumthaler et al. 1995; Ziemke et al. 2000; Seckmeyer et al. 2005). 


\section{Results and discussion}

The data of the selected 6 stations were used to follow the evolution of the ozone column over central Europe during the spring of 2020 and examine its association with Arctic ozone depletion. Before beginning this analysis, typical for the Arctic vortices features are briefly discussed making a comparison with the corresponding Antarctic phenomena.

\subsection{Ozone depletion over the polar regions and dynamical context of the 2020 Arctic episode}

An illustration of the shape and area of the Arctic vortices are exhibited in Fig. 1 through the monthly mean values of the potential vorticity (PV) at $50 \mathrm{hPa}$, which level corresponds to $18-19 \mathrm{~km}$ heights, where the maximal ozone concentration in polar regions usually takes place (Brasseur and Solomon 2005). The maps in the upper row of Fig. 1 are constructed by using the ERA-5 data (ECMWF 2021) for March of several years, and the corresponding distributions of the ozone column shown in the second row are taken from the NASA database (NASA 2021). It was assumed that PV (Hoskins et al. 1985) can outline the polar vortex, especially in the period when it is well developed. The monthly mean values of PV and ozone column were chosen to filter out the shorter time variations and to have a smoother picture. To illustrate the contrast among the Arctic and Antarctic vortices, Fig. 2 shows the same as in Fig. 1 parameters determined for October in Antarctica. The correspondence between the shape of the polar vortex and the shape of the ozone depleted area exhibited in both Figs. 1 and 2 expresses the association between the two phenomena.

It should be pointed out that the vortex and ozone patterns for 1991 and 1999 shown in Fig. 1 represent the typical cases for the Arctic within the past decades. It is seen that the PV isolines cannot depict well-shaped vortex areas like those in the Antarctic. This
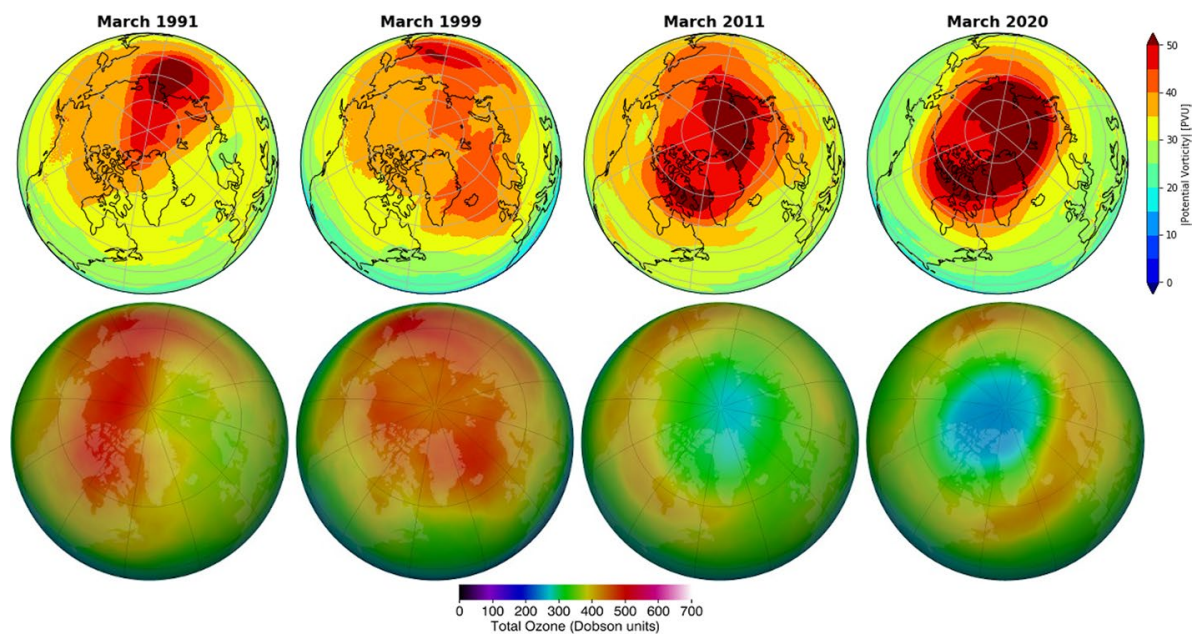

Fig. 1 Patterns of the monthly mean potential vorticity (PV, upper row) in the Arctic, extracted from the ERA5 reanalyses (ECMWF, 2021) at $50 \mathrm{hPa}$ altitude level for March of several years within the past three decades. The lower row gives the corresponding patterns of the total ozone column provided by NASA (2021) 


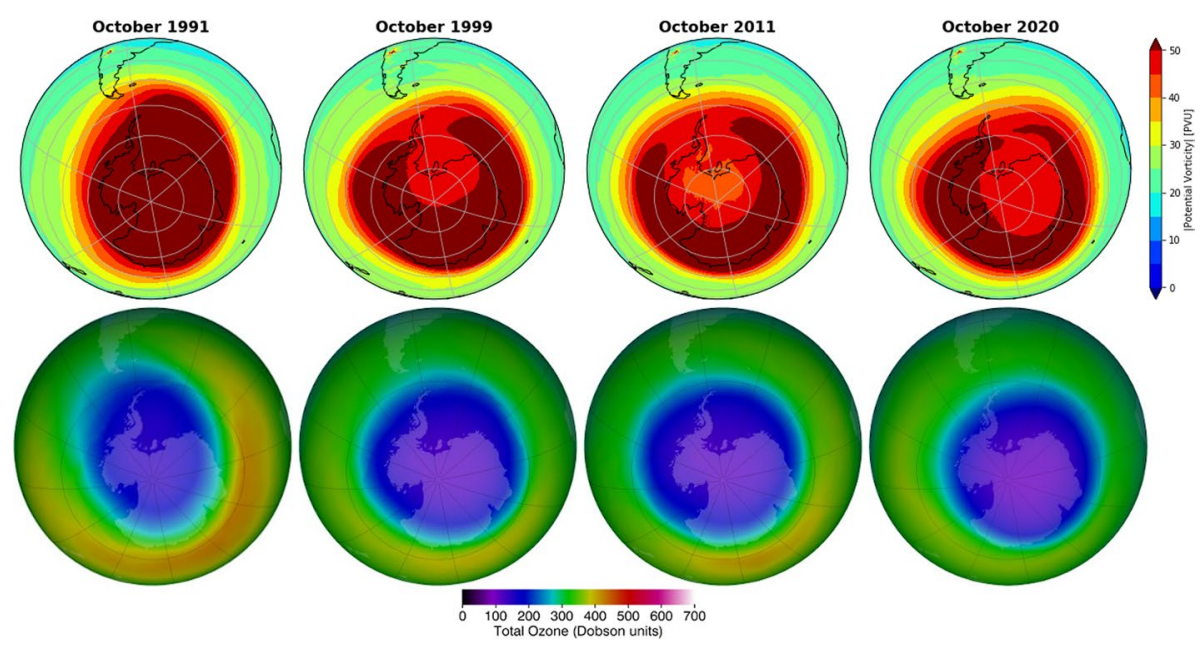

Fig. 2 The same as in Fig. 1 but for the Antarctic in October. The shape of the vortex is presented through the absolute value $|\mathrm{PV}|$ similarly to Fig. 1 that allows the same colour scale to represent the opposite vortex directions of the southern and northern hemispheres

occurrence can be accounted for the frequent breakings of the Arctic vortex during the considered month so that the monthly mean PV values turn out to be quite different than in the case of a stable vortex illustrated by Fig. 2. As a result, the ozone column distributions for 1991 and 1999 given in Fig. 1 show completely different patterns than in Antarctica. Actually, it was found that the Antarctic vortex also could be occasionally perturbed (Varotsos 2002) that affected the ozone column amounts, but such events are rare episodes rather than common cases as in the Arctic.

The long-time observations outlined the 2011 and 2020 Arctic vortices, exhibited in Fig. 1, as being unusually strong and leading to significant ozone depletion for the northern polar region. The 2020 vortex and the corresponding ozone reduction were quite similar to the marked Antarctic events (Manney et al. 2020), and namely, this episode is the subject of the present study. The breakup of the polar vortex usually intensifies the atmospheric dynamics, and a transport of poor ozone air masses to lower latitudes could be expected, which issue is discussed in the next subsection.

\subsection{The 2020 springtime ozone column over Europe according to ground-based measurements}

Figure 3 exhibits the time patterns of the ozone column in spring 2020 at the Arctic station Ny-Ålesund together with the smoothed borders of the 2.5-97.5 percentile region evaluated from the historical data of the Brewer and UV-RAD instruments (see Table 1). It is seen that both devices registered a deep reduction in the ozone column that was nearly 100 DU below the 2.5 percentile (about $330 \mathrm{DU}$ ) of the climatological level during March and April. In late April, ozone turned to the usual values, but it episodically dropped below the 2.5 percentile. These results are consistent with the observations performed by the team of the Norwegian Institute for Air Research (NILU) at Ny-Ålesund with a GUV radiometer and reported by Svendby et al. (2021). 


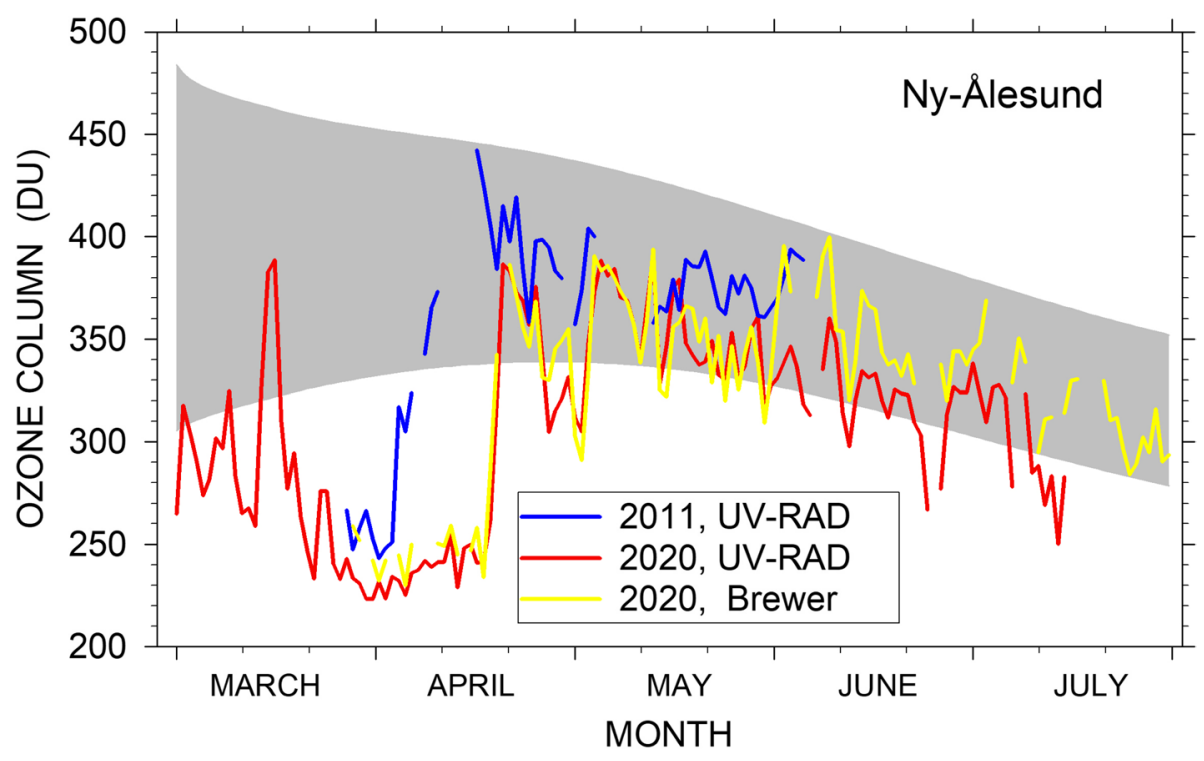

Fig. 3 Time patterns of the observed by UV-RAD and Brewer ozone column during 2020 at Ny-Ålesund. The results for 2011 are also given for comparison. The grey shadowed area represents the $2.5-97.5$ percentile zone of the climatological data provided by both instruments that contains $95 \%$ of the cases

The time patterns of the daily ozone column at the considered European stations (Table 1) for the first half of 2020 are shown in Fig. 4. The typical evolution of the ozone column at each of the stations, represented through the daily means of data provided by all operating instruments within the whole measurement period given in Table 1, is also given to outline the specific features of the 2020 behaviour. In addition, the running average with a weekly window was applied to the 2020 data to better delineate the general progress of the ozone column. The upper panel of Fig. 4 gives all these curves at the northernmost station and shows the start, development, and conclusion of the ozone depletion event that helps to follow its effect at the lower latitudes.

Figure 4 shows the appearance of well-depicted ozone minima at lower latitudes after the minimum in the Arctic. The delay of these minima concerning the minimum occurrence time at $\mathrm{Ny}$ - $\mathrm{\circ}$ lesund gradually increases moving to the south, whereas the minima deepness decreases. Figure 5 (a) exhibits the percentages of the deepest ozone column minima with respect to the mean levels and the delay of their appearance regarding NyAlesund. The former value is calculated through the ratio between the average of the ozone minima in April, presented by the blue curves in Fig. 4 and the corresponding mean amount, whereas the delay is determined by using the smoothed curves. After reaching minima, the ozone column values tend to return towards the normal values as occurred at Ny-Ålesund following a slower increase. However, it should be mentioned that the ozone decrease episodes registered at the stations below $50^{\circ} \mathrm{N}$ were appreciably longer than the corresponding ones at higher latitude and the ozone turned to the typical levels in late May and early June. Summarising, the similarities of the ozone column behaviour observed at the considered stations together with the gradually increasing delay of the ozone minima occurrences lead to the assumption about the impact of ozone depletion in the Arctic on ozone at lower latitudes. This effect becomes weaker at about $40^{\circ} \mathrm{N}$, but it is still detectable. 
Fig. 4 Time patterns of the daily ozone column (blue curves) observed in 2020 at considered ground-based stations. The corresponding mean patterns of the ozone columns, determined for each of the stations, are also given by the black curves, while the red curves represent the running averaged values of the corresponding daily ozone time patterns. The vertical dashed line indicates the day of the ozone minimum occurrence at $\mathrm{Ny}$-Ålesund, while the grey shadowed area represents the smoothed borders of the 2.5-97.5 percentile zone found from the climatological data provided by the operating at the station instruments

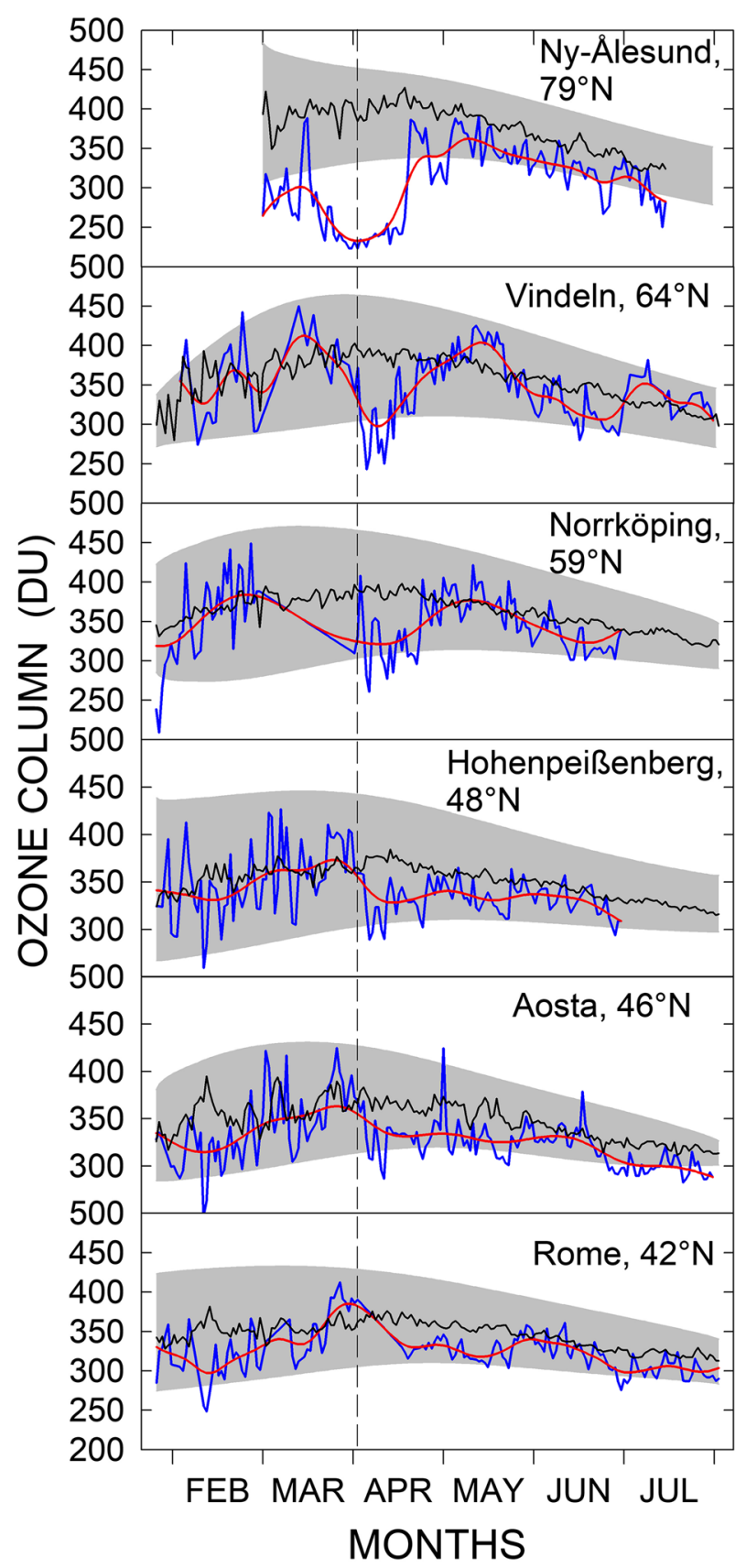

The influence of the polar vortex dynamics on the observed columnar ozone minima is investigated through the Hovmöller diagram displayed in Fig. 6. This diagram shows the time evolution of meridionally averaged daily anomalies of the meridional component of the wind (V) and the geopotential height (Z50), at the isobaric surface of $50 \mathrm{hPa}$, as a function of the longitude. The anomalies are computed relative to the 1981-2010 


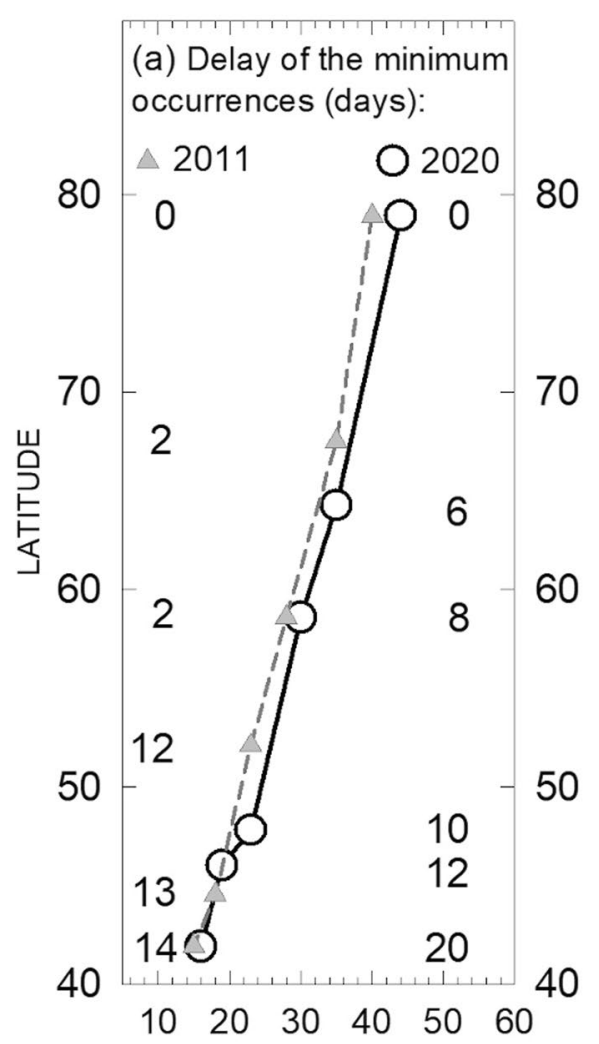

Relative ozone decrease (\%)

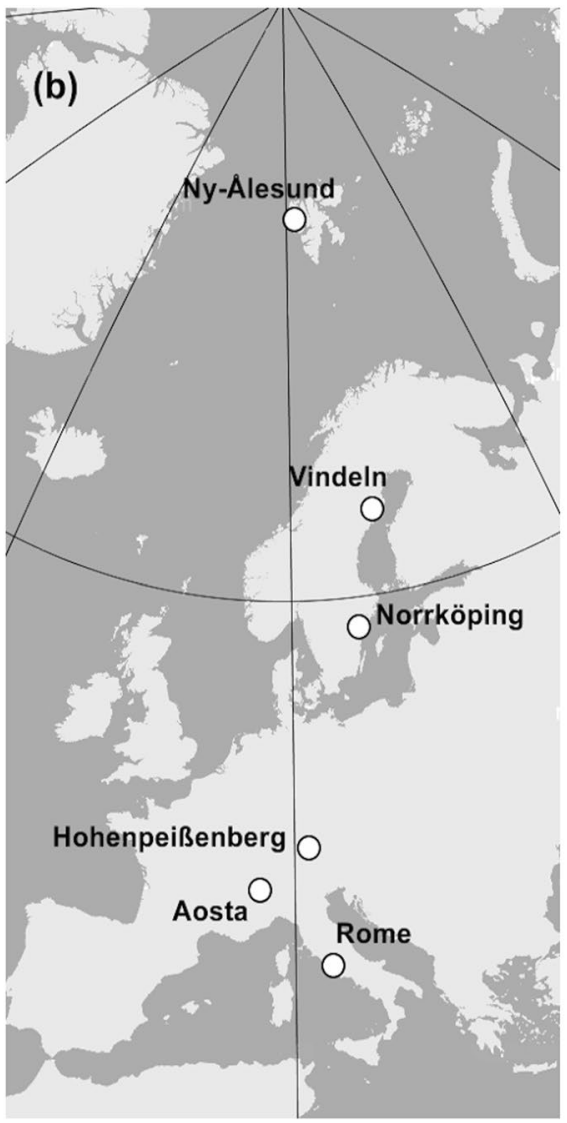

Fig. 5 a The percentage of the greatest decrease in ozone column at the considered ground-based stations found for 2020 (white circles) together with the corresponding delays of the minimum ozone occurrences. For comparison, the corresponding percentages (grey triangles) and delays, estimated for the 2011 event, are also given. $\mathbf{b}$ The geographical positions of the considered 6 stations

climatological period. Since northward V is defined as positive, a negative anomaly indicates a stronger than climate southward meridional wind component. Although the selected latitudinal band is relatively wide $\left(40-70^{\circ} \mathrm{N}\right.$ lat $)$, the meridional average still retains the large-scale features of the represented fields and encompasses all the extra-polar locations whose ozone measurements are shown in Fig. 4.

The stratospheric polar vortex was characterised by strong stability and very cold temperatures in the 2019-2020 winter quarter. Later, during the first half of March, the vortex started to lose stability in association with the upward propagation of tropospheric waves over the region of the Gulf of Alaska (Smyshlyaev et al. 2021). As a result, the stratospheric vortex weakened and displaced over the Canadian area. Figure 6 clearly shows a wide area of negative Z50 anomalies with the minimum observed around 18 March at $90^{\circ} \mathrm{W}$. This configuration was characterised by strong $\mathrm{V}$ anomalies and persisted until the first days of April. During this early spring period, the polar cap column ozone rapidly decreased reaching record-breaking values (Lawrence et al. 2020; Wohltmann et al. 2020). In April, the polar vortex moved towards the Eastern Hemisphere, where underwent the 


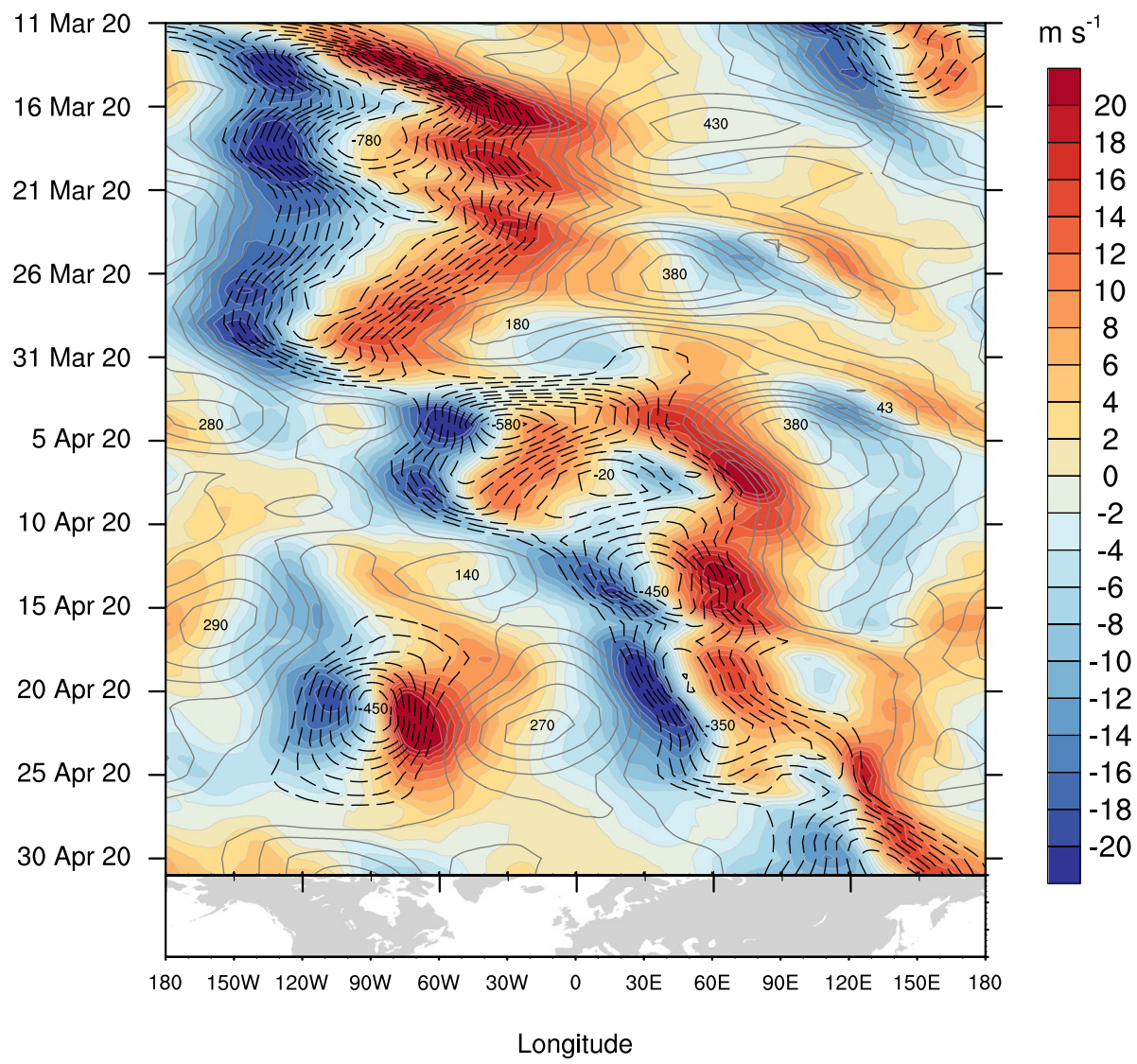

Fig. 6 Hovmöller diagram of ERA5 (ECMWF, 2021) daily anomalies of meridional wind component (m $\mathrm{s}^{-1}$; colour shaded) and geopotential height (contoured every $50 \mathrm{~m}$, black dashed contours for negative values) at $50 \mathrm{hPa}$ isosurface from 11 March 2020 to 1 May 2020. The anomalies are computed relative to the 30 -year period ending in 2010 and are averaged between $40^{\circ}$ and $70^{\circ} \mathrm{N}$ latitude

final breakdown in the second half of the month. The anomalies shown in Fig. 6 depict the eastward transition and the following formation of two different lobes, with the Euro-Asiatic portion of the vortex persisting on the region for most of April. The intense negative $\mathrm{V}$ anomaly over Europe highlights that the whole period was characterised by an advection with a strong southward component. Steering higher latitude, low ozone air masses to the south, the circulation associated with the vortex migration suggests its role in the observed evolution of the ozone column minimum shown in Fig. 4.

Bearing in mind the role of the post-vortex dynamical processes, an approximate assessment of the ozone reduction at mid-latitudes can be made assuming that the ozone deficit regarding the climatology was distributed by the winds almost homogeneously from the north polar regions to the south. In this case, if a deficit of about $150 \mathrm{DU}$, as was registered at Ny-Ålesund took place over the area above $70^{\circ} \mathrm{N}$ during the vortex, after its breakup, such a deficit should be dispersed to the south. The area above $70^{\circ} \mathrm{N}$ contains about $3 \%$ of the Earth's surface, while the region above $40^{\circ} \mathrm{N}$ is nearly $18 \%$; hence, it is greater than the former by a factor of 6 . Taking into account this relationship, it could be concluded that 
after the vortex destruction, the deficit at mid-latitudes should be 6 times lower than the initial amount of about 150 DU, or should be around 25 DU that is close to the April-May values at Aosta and Rome. Moreover, a nearly 25 DU ozone deficit can be detected with some fluctuations in all stations in Fig. 4 for the period April-July.

The discussed ozone column behaviour observed in 2020 turns out to be quite similar to that noted after the previous ozone depletion in 2011, as Figs. 3 and 5a indicate. Figure 5a shows that the dependences of the ozone decrease in 2011 and 2020 on latitude are very close to each other, and the delay in the minima occurrence approximately matches. Such similarity can be accounted for analogous dynamical conditions of the atmosphere in the Northern Hemisphere during these 2 years, which hypothesis will be a subject of future studies.

\subsection{The effect of the ozone decrease at mid-latitude on the UV irradiance at the ground}

As pointed out in Sect. 1, the capacity of the ozone to absorb solar radiation in the UV band makes it an important factor able to modulate the surface UV irradiance. Hence, it can be expected that the discussed depletion can lead to an enhancement in the surface UV irradiance, which issue is examined below.

Figure 7a shows the relative monthly averages of $I_{E}(t)$ anomalies at midday of 2020 with respect to the climatology for 2006-2020 in Aosta, Italy (see Table 1). The spectral UV data set of the Bentham 5541 operating in Aosta has been used for the calculation of erythemal

Fig. 7 Time patterns of the percentage anomaly in the monthly mean erythemal solar irradiance measured at midday in Aosta (a). Panel (b) represents analogous time patterns for the short-wave solar irradiance $(285-2800 \mathrm{~nm})$. Dotted curves indicate the 25 and 75 percentiles, respectively
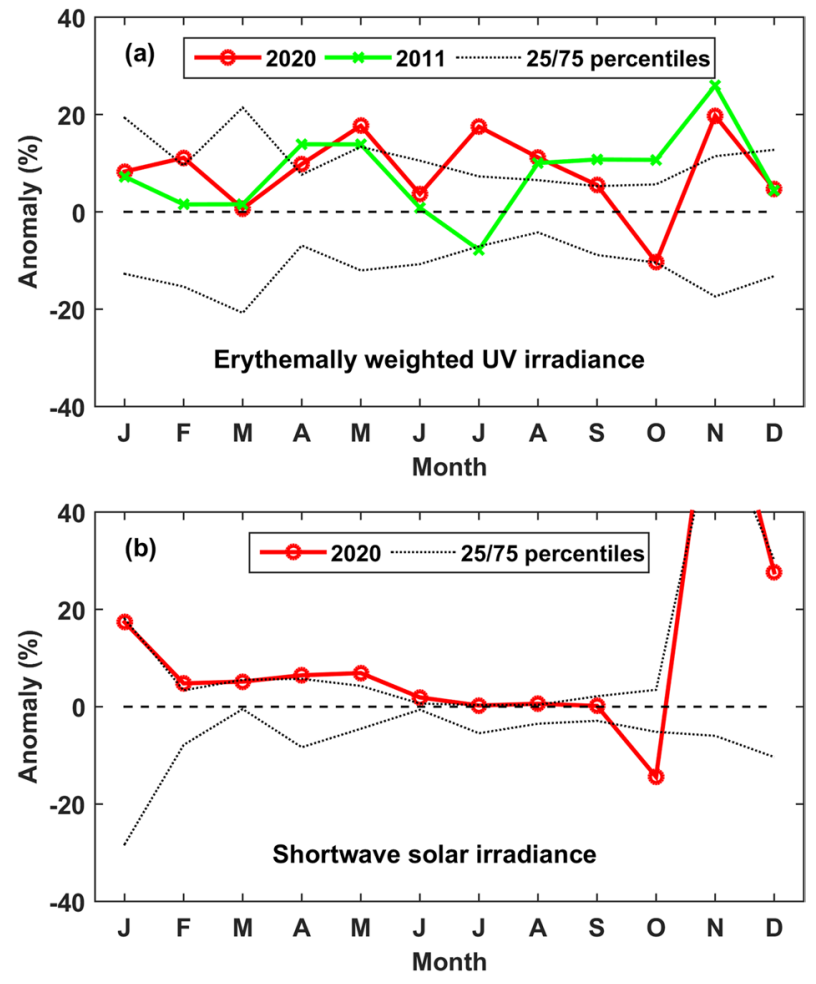
irradiance through Eq. (1). Further information on the methodology used to calculate the climatological values and the anomalies can be found in Fountoulakis et al. (2020a). An increase in $I_{E}(t)$ by about $10 \%$ and $18 \%$ in April and May, respectively, can be seen in Fig. 7a. At the beginning of April 2020, the deepest ozone column minimum is about 19\% lower than the climatology as Fig. 5a shows; however, the average April level is only about $10 \%$ lower, while in May 2020, such a mean level is approximately $8 \%$ below the climatology according to Fig. 4. Applying Eq. (2) with RAF =1.2, it can be obtained that the corresponding increase in the erythemal irradiance $I_{E}(t)$ in Aosta, resulted from the average ozone reduction, should be almost $13 \%$ in April and $10 \%$ in May that differ from the observed values. Actually, the surface UV irradiance turns out to be affected also by the cloud cover, aerosol loadings, and surface albedo besides the ozone column. The impact of the former three parameters is a quite complicated issue, and it is studied mainly by analysing the data from field measurements. In the examined case, this effect could be approximated considering the measurements of the short-wave solar irradiance (285-2800 $\mathrm{nm}$ ) performed also at Aosta. Since the UV-B band that depends on the ozone content is just a small fraction of the short-wave radiation and the rest is insensible to the ozone, it can be assumed that the behaviour of this wavelength band is affected in practice only by the clouds, aerosols, and albedo. Figure $7 \mathrm{~b}$ exhibits the anomalies of the monthly mean irradiance of this spectral range for 2020. An increase of about $8 \%$ can be noted for May, which, together with the estimated through Eq. (2) $10 \%$ increase due to the ozone, gives the value of the observed 18\% overall enhancement indicated by Fig. 7a. These approximate assessments are made under the assumption about the similar effect of the considered three factors on both UV-B and 315-2800 nm bands. However, an analogous consistency of the results for May cannot be found in April, when the observed increase in $I_{E}(\lambda)$ is about $10 \%$, while the ozone contribution was evaluated to be $13 \%$, and the increase in the short-wave irradiance is nearly $6 \%$. Such inconsistency could be associated with an incorrect value of RAF taken in the evaluation for April or with an appreciable difference in the effect of clouds, aerosols, and albedo on the UV-B band and the rest of the short-wave spectral range. The influence of these factors could be amplified by the particular weather conditions observed in 2020. In fact, the atmospheric transparency in 2020 is comparatively high, as the positive anomalies in Fig. 7b indicate. Van Heerwaarden et al. (2021) reported an enhancement in the surface solar irradiance observed in Europe in 2020 that was partly attributed to the cleaner air due to the measures against the COVID-19 and to the dry and particularly cloud-free weather. On the other hand, Diémoz et al. (2021) observed higher aerosol optical thickness at Aosta in the spring 2020, due to the advection of fine aerosol particles from the Po basin. It can be assumed that the interaction between these two competing factors, namely low cloud cover and high aerosol loadings determines the behaviour of UV irradiance in April 2020.

An increase of nearly 15\% in April and May of 2011 can be also noted in Fig. 7a, and the larger increase of UV irradiance in May 2020 with respect to 2011 can be associated with the longer-lasting ozone depletion as is evidenced in Fig. 3. It should be noticed also that the July value of UV-B radiation in 2020 is above the climatology by about $18 \%$ and appreciably exceeds the 75th percentile. Summarising, an effect of the 2020 Arctic ozone depletion on the UV-B irradiance at mid-latitudes can be assumed, but the understanding of the relationships between these two factors implies a deep, detailed study of the issue that is far from the scopes of the present report. 


\section{Conclusions}

A brief survey of the ozone column over central Europe during spring 2020 has been made to verify the hypothesis about the effect of the strong ozone depletion event that occurred in the Arctic on the ozone column at lower latitudes. For this purpose, the data sets collected at six ground-based stations distributed between $79^{\circ} \mathrm{N}$ and $42^{\circ} \mathrm{N}$ were taken into consideration, and the 2020 ozone variations at each station were compared with the corresponding average level. This approach showed a sharp drop of about $45 \%$ in the ozone column over the northernmost station at the beginning of April and fast recovering at the end of the month. Similar behaviour was observed also at the other sites, but the corresponding minima came with a delay regarding the Arctic gradually increasing from 6 to 20 days towards the southernmost station. Bearing in mind these features, it could be assumed that the ozone column at lower latitude turned out to be affected by the ozone depletion episode that occurred in the Arctic. The Hovmöller diagram of daily anomalies in the meridional wind component and geopotential height constructed for the period from the middle of March to the end of April 2020 suggests that the observed ozone reduction in the southernmost sites can be linked to the transport of higher latitude low ozone air masses. This conclusion makes the above assumption about the effect of the Arctic ozone on mid-latitudes quite realistic. The response of the ozone in Europe to the Arctic depletion event was analogous to the response observed after the 2011 depletion since the percentages of the minima at different latitudes and the delays of their occurrences were found to be appreciably similar.

Decreased ozone column at mid-latitudes may have induced high levels of solar UV radiation at the surface together with the other factors such as clouds, aerosols, and the surface albedo. Analysis of the erythemal irradiance at Aosta revealed an increase of $\sim 18 \%$ in May 2020 relative to the climatological average, and $10 \%$ of this increase can be attributed to the decreased ozone column. Since central Europe is densely populated, such large increases in UV irradiance could have significant consequences for public health.

Acknowledgements The authors gratefully acknowledge the World Ozone and Ultraviolet Radiation Data Centre (WOUDC) for providing the data set of ground-based measured ozone column, and all organisations responsible for each of the stations used here, which afford their data to WOUDC. The European Centre for Medium-Range Weather Forecasts (ECMWF) and the US National Aeronautics and Space Administration (NASA) are also acknowledged for providing data about potential vorticity and meridional winds and maps exhibiting the distribution of ozone column over the polar areas, respectively. The effort of the team working at the Italian Arctic station "Dirigibile" in Ny-Ålesund to maintain the instruments and provide the data is acknowledged, as well. This research was developed as a part of the RiS 3305 Project "Ultraviolet Irradiance Variability in the Arctic".

\section{Declarations}

Conflict of interest The authors declare no competing interests.

\section{References}

Bernhard GH, Fioletov VE, Grooß J-U, Ialongo I, Johnsen B, Lakkala K, Manney GL, Müller R, Svendby T (2020) Record-breaking increases in Arctic solar ultraviolet radiation caused by exceptionally large ozone depletion in 2020. Geophys Res Lett 47:e2020GL090844. https://doi.org/10.1029/2020GL0908 44. 
Blumthaler M, Salzgeber M, Ambach W (1995) Ozone and ultraviolet-B irradiances: experimental determination of the radiation amplification factor. Photochem Photobiol 61:159-162. https://doi.org/10. 1111/j.1751-1097.1995.tb03954.x

Brewer AW, Kerr JB (1973) Total ozone measurements in cloudy weather. Pure Appl Geophys 106-108:928-937

Brasseur GP, Solomon S (2005) Aeronomy of the middle atmosphere. Springer

C.I.E. (Commission Internationale de l'Eclairage). Erythema reference action spectrum and standard erythema dose. CIE S007E-1998. 1998. CIE Central Bureau, Vienna, Austria

Dameris M, Loyola DG, Nützel M, Coldewey-Egbers M, Lerot C, Romahn F, van Roozendael M (2021) Record low ozone values over the Arctic in boreal spring 2020. Atmos Chem Phys 21:617-633. https:// doi.org/10.5194/acp-21-617-2021

Diémoz H, Magri T, Pession G, Tarricone C, Tombolato IKF, Fasano G, Zublena M (2021) Air quality in the Italian Northwestern Alps during year 2020: Assessment of the COVID-19 «Lockdown Effect» from multi-technique observations and models. Atmosphere 12:1006

Dobson GMB (1968) Forty years' research on atmospheric ozone at Oxford: a history. Appl Opt 7:387-405. https://doi.org/10.1364/AO.7.000387.PMID20068600

ECMWF (European Centre for Medium-Range Weather Forecasts), ERA-5 reanalyses (https://cds.climate. copernicus.eu/\#!/home), last accessed in April 2021.

Farman JC, Gardiner BG, Shanklin JD (1985) Large losses of total ozone in Antarctica reveal seasonal C1Ox/NOx interaction. Nature 315:207-210

Fountoulakis I, Diémoz H, Siani AM, Hülsen G, Gröbner J (2020) Monitoring of solar spectral ultraviolet irradiance in Aosta, Italy. Earth Syst Sci Data 12:2787-2810. https://doi.org/10.5194/ essd-12-2787-2020,2020

Fountoulakis I, Diémoz H, Siani A-M, Laschewski G, Filippa G, Arola A, Bais AF, De Backer H, Lakkala K, Webb AR, De Bock V, Karppinen T, Garane K, Kapsomenakis J, Koukouli M-E, Zerefos CS (2020b) Solar UV irradiance in a changing climate: trends in Europe and the significance of spectral monitoring in Italy. Environments 7:1. https://doi.org/10.3390/environments7010001

Garane K, Lerot C, Coldewey-Egbers M, Verhoelst T, Koukouli ME, Zyrichidou I, Balis DS, Danckaert T, Goutail F, Granville J, Hubert D, Keppens A, Lambert J-C, Loyola D, Pommereau J-P, Van Roozendael M, Zehner C (2018) Quality assessment of the Ozone_cci Climate Research Data Package (release 2017) - Part 1: Ground-based validation of total ozone column data products. Atmos Meas Tech 11:1385-1402. https://doi.org/10.5194/amt-11-1385-2018

Hauchecorne A, Godin S, Marchand M, Hesse B, Souprayen C (2002) Quantification of the transport of chemical constituents from the polar vortex to midlatitudes in the lower stratosphere using the highresolution advection model MIMOSA and effective diffusivity. J Geophys Res 107:8289. https://doi. org/10.1029/2001JD000491

Hoskins BJ, McIntyre ME, Robertson AW (1985) On the use and significance of isentropic potential-vorticity maps. Q J R Meteorol Soc 111:877-946

Kerr JB, McElroy CT, Olafson RA (1981) Measurements of total ozone with the Brewer spectrophotometer. In Proceedings of the Quadrennial Ozone Symposium (London J ed) 74-79, Natl. Cent. for Atmos. Res., Boulder, Colorado.

Knudsen BM, Grooß J-U (2000) Northern midlatitude stratospheric ozone dilution in spring modeled with simulated mixing. J Geophys Res 105:6885-6890

Koch G, Wernli H, Buss S, Staehelin J, Peter T, Liniger MA, Meilinger S (2004) Quantification of the impact in mid-latitudes of chemical ozone depletion in the 1999/2000 Arctic polar vortex prior to the vortex breakup. Atmos Chem Phys D 4:1911-1940

Komhyr WD, Grass RD, Leonard RK (1989) Dobson spectrophotometer 83: a standard for total ozone measurements, 1962-1987. J of Geophys Res 94:9847. https://doi.org/10.1029/jd094id07p09847

Lawrence ZD, Perlwitz J, Butler AH, Manney GL, Newman PA, Lee SH, Nash ER (2020) The remarkably strong Arctic stratospheric polar vortex of winter 2020: Links to record-breaking Arctic oscillation and ozone loss. J Geophys Res Atmos 125. https://doi.org/10.1029/2020JD033271

Madronich S, (1993) UV radiation in the natural and perturbed atmosphere. in: Tevini, M. (Ed.), Environmental Effects of UV (Ultraviolet) Radiation. Lewis, Boca Raton, Florida, USA

Manney GL et al (2011) Unprecedented Arctic ozone loss in 2011. Nature 478:469-475

Manney GL, Livesey NJ, Santee ML, Froidevaux L, Lambert A, Lawrence ZD, Millán LF, Neu JL, Read WG, Schwartz MJ, Fuller RA (2020) Record-low arctic stratospheric ozone in 2020: MLS observa-

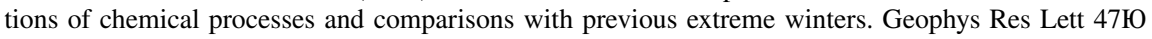
e2020GL089063. https://doi.org/10.1029/2020GL089063

Molina MJ, Rowland FS (1974) Stratospheric sink for chlorofluoromethanes: chlorine atom catalysed destruction of ozone. Nature 249:810-814 
NASA (USA National Aeronautics and Space Administration) (https://ozonewatch.gsfc.nasa.gov/), last accessed in April 2021

Petkov BH, Vitale V, Mazzola M, Lupi A, Lanconelli C, Viola A, Busetto M (2016) Variability features associated with ozone column and surface UV irradiance observed over Svalbard from 2008 to 2014. Rendiconti Lincei Scienze Fisiche e Naturali 27(Suppl 1):S25-S32

Petkov BH, Vitale V, Tomasi C, Siani AM, Seckmeyer G, Webb AR, Smedley ARD, Casale GR, Werner R, Lanconelli C, Mazzola M, Lupi A, Busetto M, Diémoz H, Goutail F, Köhler U, Mendeva BD, Josefsson W, Moore D, Bartolomé ML, González JRM, Mišaga O, Dahlback A, Tóth Z, Varghese S, De Backer H, Stübi R, Vaníček V (2014) Response of the ozone column over Europe to the 2011 Arctic ozone depletion event according to ground-based observations and assessment of the consequent variations in surface UV irradiance. Atmos Envir 85:169-178

Petkov B, Vitale V, Tomasi C, Bonafé U, Scaglione S, Flori D, Santaguida R, Gausa M, Hansen G, Colombo $\mathrm{T}$ (2006) Narrow-band filter radiometer for ground-based measurements of global UV solar irradiance and total ozone. Appl Opt 45:4383-4395

Seckmeyer G, Bais A, Bernhard G, Blumthaler M, Booth CR, Lantz K, McKenzie RL (2005) Instruments to measure solar ultraviolet radiation, part 2: broadband instruments measuring erythemally weighted solar irradiance. WMO-GAW report No.164

Siani AM, Frasca F, Scarlatti F, Religi A, Diémoz H, Casale GR, Pedone M, Savastiouk V (2018) Examination on total ozone column retrievals by Brewer spectrophotometry using different processing software. Atmos Meas Tech 11:5105-5123. https://doi.org/10.5194/amt-11-5105-2018

Solomon S, Garcia RR, Rowland FS, Wuebbles DJ (1986) On the depletion of Antarctic ozone. Nature 321:755-758. https://doi.org/10.1038/321755a0

Smyshlyaev SP, Vargin PN, Lukyanov AN, Tsvetkova ND, Motsakov MA (2021) Dynamical and chemical processes contributing to ozone loss in exceptional Arctic stratosphere winter-spring of 2020. Atmos Chem Phys Discuss. https://doi.org/10.5194/acp-2021-11

Stamnes K, Slusser J, Bowen M (1991) Derivation of total ozone abundance and cloud effects from spectral irradiance measurements. Appl Opt 30:4418-4426

Svendby TM, Johnsen B, Kylling A, Dahlback A, Bernhard GH, Hansen GH, Petkov B, Vitale V (2021) GUV long-term measurements of total ozone column and effective cloud transmittance at three Norwegian sites. Atmos Chem Phys 21:7881-7899. https://doi.org/10.5194/acp-21-7881-2021

Vanicek K (2006) Differences between ground Dobson, Brewer and satellite TOMS-8, GOME-WFDOAS total ozone observations at Hradec Kralove Czech. Atmos Chem Phys 6:5163-5171

Van Heerwaarden CC, Mol WB, Veerman MA, Benedict I, Heusinkveld BG, Knap WH, Kazadzis S, Kouremeti N, Fiedler S (2021) Record high solar irradiance in Western Europe during first COVID19 lockdown largely due to unusual weather. Commun Earth Environ 2:37. https://doi.org/10.1038/ s43247-021-00110-0

Van Roozendael M et al (1998) Validation of ground-based visible measurements of total ozone by comparison with Dobson and Brewer spectrophotometers. J Atmos Chem 29:55-83

Varotsos C (1994) Solar ultraviolet radiation and total ozone, as derived from satellite and ground-based instrumentation. Geophys Res Lett 21:1787-1790

Varotsos C (2002) The southern hemisphere ozone hole split in 2002. Environ Sci Pollut Res 9:375-376

Varotsos CA, Cracknell AP, Tzanis C (2012) The exceptional ozone depletion over the Arctic in JanuaryMarch 2011. Remote Sens Lett 3:343-352. https://doi.org/10.1080/01431161.2011.597792

Varotsos CA, Efstathiou MN, Christodoulakis J (2020) The lesson learned from the unprecedented ozone hole in the Arctic in 2020; A novel nowcasting tool for such extreme events. J Atmos Sol-Terr Phys 207:105330

WMO (2018) Scientific assessment of ozone depletion: 2018. Geneva, Switzerland: Global Ozone Res and Monit Proj: Rep 58. https://ozone.unep.org/sites/default/files/2019-05/SAP-2018-Assessment-report. pdf. Accessed Mar 2021

Wohltmann I, von der Gathen P, Lehmann R, Maturilli M, Deckelmann H, Manney GL, Davies J, Tarasick D, Jepsen N, Kivi R, Lyall N, Rex M (2020) Near-complete local reduction of arctic stratospheric ozone by severe chemical loss in spring 2020. Geophys Res Lett 47:e2020GL089547. https://doi.org/ 10.1029/2020GL089547

WOUDC (World Ozone and Ultraviolet Data Centre), http://woudc.org, last accessed in October 2020

Ziemke JR, Chandra S, Herman J, Varotsos C (2000) Erythemally weighted UV trends over northern latitudes derived from Nimbus 7 TOMS measurements. J Geophys Res 105:7373-7382 


\section{Authors and Affiliations}

Boyan Petkov ${ }^{1,2} \cdot$ Vito Vitale $^{2} \cdot$ Piero Di Carlo $^{1,3} \cdot$ Mauro Mazzola $^{2} \cdot$ Angelo Lupi $^{2}$. Henri Diémoz ${ }^{4}$ - Ilias Fountoulakis ${ }^{4}$. Oxana Drofa ${ }^{5} \cdot$ Daniele Mastrangelo $^{5}$. Giuseppe Rocco Casale ${ }^{6}$. Anna Maria Siani ${ }^{6}$

1 Department of Advanced Technologies in Medicine \& Dentistry, University G. d'Annunzio, Via dei Vestini, 30-66100, Chieti-Pescara, Italy

2 Institute of Polar Sciences, National Research Council (CNR-ISP), Via P. Gobetti 104, 40129 Bologna, Italy

3 Center for Advanced Studies and Technology-CAST, Chieti, Italy

4 ARPA Valle d'Aosta, Loc. Grande Charrière, Saint-Christophe, Aosta, Italy

5 Institute of Atmospheric Sciences and Climate, National Research Council (CNR-ISAC), Via P. Gobetti 104, 40129 Bologna, Italy

6 Department of Physics, Sapienza University, Rome, Piazzale Aldo Moro 5, 00185 Rome, Italy 